\title{
Determination of the prevalence of blaoxa-like gene and ISAbal elements among extensive-drug resistant (XDR) Acinetobacter boumannii isolates
}

Salah Mohsin ${ }^{1}$, Wasan Abdul-Elah Bakir ${ }^{1}$, Majeed Arsheed ${ }^{2}$

DOI. 10.21931/RB/2021.06.04.25

Abstract: The capacity of Multi-drug resistant (MDR) Acinetobacter baumannii to survive in any state of affairs concerning the gaining of various gene types of virulence and antimicrobial agent resistance are the main anxiety in the hospital's environments. So, it is very crucial to determine the prevalence of insertion sequences in A. baumannii in the hospitals. Detecting the blaoxa-51 gene through the polymerase chain reaction (PCR) was performed to confirm Acinetobacter baumannii and the search for ISAbal element. Between October 2020 and February 2021, 540 distinct clinical specimens were gathered from five hospitals in Baghdad. Thirty-eight $A$. baumannii isolates were obtained from various clinical specimens. The isolates were initially identified phenotypically using standard microbiological techniques and by the Vitek2 compact automated machine. Isolates of $A$. baumannii were identified genotypically by amplification of the blaoxa-51-like gene. Antimicrobials are studied by Kirby-Bauer (disc diffusion) technique on Muller-Hinton agar as specified by the recent clinical and laboratory standard institute (CLSI) guidelines (2020). The actual results of the current study indicated that from total isolated (38) A.baumannii isolates, 23 isolates (61\%) were resistant to meropenem and 25 isolates (66\%) were resistant to imipenem. The blaoxa-51 gene was identified in all strains examined, ISAbal was also present in all A. baumannii isolates. ISAbal has a high predominance between drug-resistant $A$. baumannii. Identifying these parameters can assist in the control of infection and decreasing the microorganism's prevalence rate.

Key words: Insertion sequence, The blaoxa-51-like gene, Acinetobacter baumannii.

\section{Introduction}

An opportunistic infectious agent, A.baumannii encompasses a high rate of occurrence among immunocompromised people, significantly those that have experienced long (more than ninety days) hospital residence ${ }^{1}$. Commonly related to aquatic environments ${ }^{2}$. It's been recognized as a "red alert" human infectious agent in recent years, causing concern among medical professionals, owing to its extensive spectrum of antibiotic resistance ${ }^{3}$.

The development of multidrug-resistant (MDR) pathogens has more and more become a cause for profound importance concerning each healthcare facility and community-acquired infections ${ }^{4}$. According to the World Health Organization (WHO), Antimicrobial resistance has recently been recognized in concert as one of the 3 most vital issues facing human heal$t^{5}$. The therapeutic selections are restricted, typically leading to unsuitable medical care and resulting negative consequences on patient ${ }^{6}$.

The primary antibiotic resistance mechanisms are enzymatic (production of $\beta$-lactamases and enzymatic modification of aminoglycosides) and non-enzymatic (changing membrane permeability, activating efflux pumps) and altering of the target site $)^{7}$.

Insertion sequences (IS) are among the most basic mobile genetic elements (MGEs) and are found across the animal kingdom. To present, more than 4500 IS from 29 families have been discovered ${ }^{8,9}$. In Acinetobacter spp., more than thirty different types of Insertion Sequences have been discovered, suggesting that ISs had a significant role in developing this species and contributing to the multidrug-resistant phenotype shown in this genus ${ }^{10}$.

Insertion elements have two distinct characteristics: short transposable elements (up to 2500bp) and only code for proteins involved in transposition ${ }^{11}$.

In A. baumannii, ISAbal has been found in conjunction with numerous antibiotic resistance genes ${ }^{12}$. ISAbal has been shown to function in the expression of the Bla ampC gene, the antibiotic resistance gene of $A$. baumannii, which encodes the naturally occurring cephalosporins enzyme, and the blaOXA-23 gene, which encodes a carbapenem-degrading oxacillinase. Nevertheless, it could also act in the case of other resistance genes ${ }^{13,14}$. A composite transposon (defined as Tn2006) formed by two copies of ISAbal bracketing this $\beta$-lactamase gene, responsible for the movement of blaOXA-2315.

ISAbal has been found to regulate the expression of the bla ampC gene, which encodes the naturally occurring cephalosporins enzyme, and the blaOXA-23 gene, which encodes a carbapenem-hydrolyzing oxacillinase enzyme. However, it may also play a role in the development of additional resistance genes. ISAbal has been demonstrated to produce carbapenem resistance in $A$. baumannii by causing overexpression of the naturally existing blaoxa-51-like gene ${ }^{16}$.

The expression of the blaOXA-23 gene has been linked to ISAbal and ISAba415,17. The expression of the blaOXA-58 gene has been related to the insertion sequences ISAba1, ISAba2, ISAba3, and $I S 18^{18}$. Therefore, determining the prevalence of insertion sequences genes in A. baumannii in hospitals is very crucial.

\section{Materials}

\section{Specimens' collection}

Between October 2020 and February 2021, 540 distinct clinical specimens were collected from five hospitals in Baghdad, including The Burns Hospital, Gazi Al-Hariri Hospital, Baghdad Teaching Hospital, Welfare Teaching Hospital in the Medical City, and Al-Yarmouk teaching hospital. Collected

\footnotetext{
${ }^{1}$ Department of Microbiology, College of Medicine, Mustansiriyah University, Baghdad, Iraq.

${ }^{2}$ Gene bank Department, Forensic DNA for research and training Centre, Al-nahrain University, Baghdad, Iraq.
} 
specimens were sputum, blood, fluids such as (cerebrospinal, pleural, and peritoneal), urine, and swabs.

\section{Isolation of Bacteria}

In the laboratory (Teaching Laboratories/Medical City, Baghdad) under aseptic conditions, the collected specimens were cultured directly on MacConkey agar and blood agar, incubated for $24 \mathrm{hrs}$. at $37^{\circ} \mathrm{C}$. The colonies were non-hemolytic opaque creamy on blood agar, while on MacConkey agar were non-lactose fermenting colonies. For obtaining pure, well-isolated colonies, they were subcultured on another MacConkey agar plate and incubated for another $24 \mathrm{hrs}$. at $37^{\circ} \mathrm{C}^{19}$.

\section{Bacterial Identification}

\section{Microscopical examination}

One isolated colony was transferred to a microscopic slide, fixed then stained with Gram stain (GS). Gram reaction, cell shape, and arrangement were recorded. The results were compared with Brooks et al. $(2013)^{20}$.

\section{Biochemical tests}

To phenotypically identify the isolates as A. baumannii, biochemical tests such as the ability to grow at $42^{\circ} \mathrm{C}$, culture on selective medium, negative for oxidase test, absence of lactose fermentation, and others were utilized.

\section{Identification of Acinetobacter baumannii using VITEK ${ }^{\circledR} 2$ system.}

As stated by the manufacturer's instructions, identification cards of Gram-Negative Bacteria (ID-GNB) were used on the $\mathrm{VITEK}{ }^{\circledR} 2$ system to recognize isolates at the species level. The bacterial isolates were inoculated at $37^{\circ} \mathrm{C}$ on MacConkey agar plates and, after incubated overnight, taken a single colony then suspended. In $0.45 \%$ sodium chloride, the turbidity measurement for the bacterial suspension to meet the McFarland (0.5) standards, The (Gram-Negative Vitek 2 Identity card) then was manually placed into the Vitek-2 system, along with the bacterial suspension tub, the software also prepared according to (BioMerieux, France) the manufacturer's instructions ${ }^{21}$.

\section{Identification of A.baumannii by PCR}

Using a primer specific for bla OXA51-like genes, PCR was utilized to amplify bla OXA51-like genes used for A. baumannii isolate recognition.

\section{Test of antimicrobial susceptibility profile}

According to the latest clinical and laboratory standard institute (CLSI) criteria (2020), the isolates were tested for antimicrobial susceptibility to 18 antimocrobial agents using the Kirby-Bauer disc diffusion technique on Muller-Hinton agar (Oxoid /England) ${ }^{22}$. The antibiotic discs (Mast Group /UK) used throughout the study for A.baumannii isolates are PiperacillinTazobactam (100/10 $\mu \mathrm{g} /$ disc), Ampicillin-sulbactam (13/10 $\mu \mathrm{g} /$ disc), Ticarcillin-Clavulanate (55/13 $\mu \mathrm{g} /$ disc), Cefepime(33 $\mu \mathrm{g} / \mathrm{disc})$, Cefotaxime (33 $\mu \mathrm{g} / \mathrm{disc})$, Ceftazidime (33 $\mu \mathrm{g} / \mathrm{disc})$, Ceftriaxone (33 $\mu \mathrm{g} / \mathrm{disc})$, Imipenem (13 $\mu \mathrm{g} / \mathrm{disc})$, Meropenem (13 $\mu \mathrm{g} /$ disc), Colistin sulphate $(25 \mu \mathrm{g} /$ disc), Tobramycin $(13 \mu \mathrm{g} /$ disc), Gentamicin (13 $\mu \mathrm{g} /$ disc), Amikacin (33 $\mu \mathrm{g} / \mathrm{disc})$, Doxycycline(30 $\mu \mathrm{g} / \mathrm{disc})$, Tetracycllin (30 $\mu \mathrm{g} / \mathrm{disc})$, Ciprofloxacin $(5 \mu \mathrm{g} / \mathrm{disc})$, Levofloxacin $(5 \mu \mathrm{g} / \mathrm{disc})$ and Trimethoprime-Sulphamethoxazole(1.25/23.55 $\mu \mathrm{g} / \mathrm{disc})$.

\section{Genomic DNA extraction from bacterial isolates}

Extraction of bacterial DNA from isolates under study using a commercial Extraction system (ZR Fungal/Bacterial DNA Miniprep Kit) designed to isolate DNA from Gram-negative bacteria according to the manufacturer's instructions. For each reaction, a totally of $4 \mu \mathrm{l}$ of extracted DNA was used.

\section{Molecular recognition of BlaOXA-51-like gene and Insertion sequence elements}

To detect XDR A.baumannii isolates, PCR was used to detect the Bla-OXA-51-like gene and ISAbal elements. Primer sequences for each gene reported above are listed in table (1). These primers (Macrogen, South Korea) were received in a lyophilized state, dissolved in sterile deionized distilled water

\begin{tabular}{|l|l|c|l|}
\hline Primer & The sequence of primers (5' ---3') & Product size & Accession number \\
\hline OXA51 & CTTTTTGGCTAAATGGAAGCG & 434 & \multirow{2}{*}{ CP081137.1 } \\
\cline { 1 - 2 } OXA51 & CGGGTGTCTTAGTTATCCAAC & & \\
\hline ISAba1 F & CACGAATGCAGAAGTTG & 549 & CP029569.1 \\
\cline { 1 - 2 } ISABa1 & CGACGAATACTATGACAC & & \\
\hline
\end{tabular}

Table 1. Sequences of primers used throughout the study.

\begin{tabular}{|l|l|l|l|}
\hline Steps & OXA-51 & ISAba1 & Repeats \\
\hline Activation & $94^{\circ} \mathrm{C} / 5 \mathrm{~min}$ & $94^{\circ} \mathrm{C} / 5 \mathrm{~min}$ & 1 cycle \\
\hline Denaturation & $94^{\circ} \mathrm{C} / 45 \mathrm{~s}$ & $94^{\circ} \mathrm{C} / 45 \mathrm{~s}$ & \multirow{2}{*}{40 cycles } \\
\cline { 1 - 2 } Annealing & $56^{\circ} \mathrm{C}$ & $50^{\circ} \mathrm{C}$ & \\
\cline { 1 - 2 } & $72^{\circ} \mathrm{C} / 45 \mathrm{~s}$ & $72^{\circ} \mathrm{C} / 45 \mathrm{~s}$ & \\
\hline Final extension & $72^{\circ} \mathrm{C} / 7 \mathrm{~min}$ & $72^{\circ} \mathrm{C} / 7 \mathrm{~min}$ & - \\
\hline
\end{tabular}

Table 2. Programs were used in the PCR for OXA-51-like gene and ISAbal element. 
to a final concentration of 100 picomole/ $\mu$ l, and kept in a deep freezer until use, as advised by the vendor.

The PCR amplification procedure for the genetic level to detecting genes under study by follows steps: Final volume for PCR mixture was $25 \mu \mathrm{l}$ (12.5 of Green Master Mix 2x, $4 \mu \mathrm{l} \mathrm{ex-}$ tracted template DNA, $1.5 \mu \mathrm{l}$ from each forward and reverse primer, $5.5 \mu \mathrm{l}$ nuclease-free water were added in $0.2 \mathrm{ml}$ PCR Eppendorf tubes, mixed for a short time via vortex then been loaded to Veriti ${ }^{\mathrm{T}}$ 96-Well (applied biosystems) Thermal Cycler. The program used for each monoplex PCR reaction was set according to each primer. The best annealing temperature was chosen after the gradient runs through the optimization process of each oligonucleotide primer.

For amplification of the Bla-OXA-51-like gene, the DNA thermal cycler device Veriti ${ }^{\mathrm{T}}$ 96-Well (applied biosystems) was programmed in the following amplification conditions: Following a 5-minute activation at $94^{\circ} \mathrm{C}, 40$ cycles of 45 seconds at $94^{\circ} \mathrm{C}$ (denaturation), $56^{\circ} \mathrm{C}$ (annealing), and 45 seconds at $72^{\circ} \mathrm{C}$ (extension) were conducted. In contrary to other genes, the ISAbal annealing temperature was $50^{\circ} \mathrm{C}$. The last cycle was followed by 7 minutes at $72^{\circ} \mathrm{C}$ (Table 2). Amplified PCR products were examined on $1.5 \%$ agarose gel at an electrical current of 7 volt $\mid \mathrm{cm} 2$ in 1 X TBE buffer with added Red safe dye (INTRON) has been exposed till the tincture had reached the other side of the gel. The SiZer ${ }^{\mathrm{TM}}$-1000 Plus DNA Marker and SiZer ${ }^{\text {TM }}$-100 DNA Marker (Intron / Korea) were used as markers during PCR products electrophoresis. After that, the agarose gel was removed from the tank and visualized by a UV transilluminator documentation system (Cleaver scientific /UK) at $336 \mathrm{~nm}$, then photographed using a digital camera.

Sequencing was carried out by Macrogen DNA Sequencing (Seoul, Korea) using 3730xl DNA Analyzer (Applied Biosystems ${ }^{T M}$, Foster City, CA). Two samples from ISAbal PCR products with forwarding primer $(17 \mathrm{pmol} / \mu \mathrm{l})$ for each gene were selected and sent to sequencing. Raw reads generated in this study were trimmed or filtered to remove low-quality sequences using (SnapGene software). Once sequencing reads had been obtained, the data analysis process was started, the Basic Local Alignment Search Tool (BLAST) of the National Center for Biotechnology Information (NCBI) was used to analyze DNA sequences and do similarity searches.

\section{Results}

540 clinical specimens were collected between October 2020 and February 2021 from some hospitals in Baghdad, including Baghdad medical city and Al-Yarmouk hospitals. Thirty-eight bacterial isolates were obtained, which differentiated to A.baumannii. Following conventional identification techniques, antimicrobial sensitivity testing was carried out by examining the findings in (Figure 1), revealing a high degree of resistance of A.baumannii clinical isolates to the majority of the antimicrobial agents under test.

In this study, antibiotic resistance profile of Acinetobacter baumannii for 18 antibiotics as following: Trimethoprime/sulphamethoxazole 32 (84\%), Ciprofloxacin 27 (71\%), Piperacillin/ tazobactam 26(68\%), Ticarcillin/clavulanate 26 (68\%),Ceftazidime 26(68\%), Ceftriaxone26(68\%), Cefotaxime 25 (66\%), Imipenem 25(66\%), Doxycycline 26(68\%), Levofloxacin 25 (66\%),Cefepime 24(63\%), Tetracycline 24(63\%), Meropenem 23(61\%), Gentamicin 22 (58\%), Tobramycin 15(39\%), Amikacin 17(45\%), Ampicillin/sulbactam 12 (32\%), Colistin O(0\%). The exact and important results of current study indicated that from total isolated (38) A.baumannii isolates, 23 isolates (61\%) and 25 isolates (66\%) were resistant to meropenem and imipenem respectively.

All the A. baumannii isolates were positive for blaoxa51-like genes and ISAbal genes. Figures 1 and 2 demonstrate agarose gel electrophoresis of PCR products of blaoxa-51-like genes and ISAbal elements, respectively.

The sequence was analyzed by BLAST software at NCBI. Figure (4) shows the alignment result with the USA: San Diego isolates (Accession number CP053098.1). The sequence was found to share $99 \%$ nucleotide homology with the reference isolates. Tables 3 and 4 show nucleotide changes and Features of ISAba1(Forward) from Acinetobacter baumannii (X9 isolate) with Acinetobacter baumannii ATCC 17978 chromosome from the USA: San Diego.

The sequence was analyzed by BLAST software at NCBI. Figure (4) shows the alignment result with USA: San Diego isolates (Accession number CP050388.1). The sequence was found to share 99\% nucleotide homology with the reference isolates. Tables 5 and 6 show the nucleotide changes and features of ISAbal(Forward) from Acinetobacter baumannii (X10 isolate) with Acinetobacter baumannii strain VB473 chromosome from India.

\section{Discussion}

A. baumannii has developed as a well-established nosocomial pathogen with a high level of antibiotic resistance. Various medical facilities frequently report extensively drug-resistant, and pan drug-resistant isolates ${ }^{23}$. By 2007, up to 70\% of isolates in specific locations had evolved multidrug resistance, particularly resistance to carbapenems, which were formerly thought to be the gold standard for treating MDR A. baumannii infections ${ }^{24}$.

The antibiotic of choice for treating $A$. baumannii is carbapenems. Due to rising resistance rates, A. baumannii infections are becoming increasingly ineffectual. Resistance to the newer antibiotic tigecycline is also quickly developing. Colistin, a previously abandoned antibiotic, is now used as a last option, yet resistance to this medication is increasing at an alarming pace throughout the world ${ }^{23}$.

Aside from its proclivity for the critically ill in intensive care units, $A$. baumannii has lately been linked to a slew of infectious diseases among military troops injured in the Iraq and Afghanistan wars ${ }^{4}$.

Resistance of Carbapenem is frequently connected to the making of oxacillinase enzymes. Metallo $\beta$-lactamases (MBL), on the other hand, can cause carbapenem resistance in $A$. baumannii ${ }^{25}$.

The actual results of the current study indicated that of 38 A.baumannii isolates, 23 isolates (61\%) and 25 isolates (66\%) were resistant to meropenem and imipenem, respectively. The antibiotic resistance results of imipenem and meropenem are less than that found by al Al-Saadi (2018) ${ }^{26}$. From 162 A.baumannii isolates, 112 isolates (88.19\%) and 107 (84.25\%) were resistant to meropenem and imipenem, respectively. Prior investigators in Iran found that the resistance rates to imipenem and meropenem were (95.23\%) and (98.09\%) respectively ${ }^{27}$, indicating that these bacteria have a wide range of resistance mechanisms. This would imply significant risks among hospitalized patients, mainly where this antibiotic class was previously considered the standard therapy for A.baumannii infections ${ }^{28}$.

The recognition of the Bla OXA-51-like gene can be utilized to identify A.baumannii reliably and straightforwardly ${ }^{29,30}$. 


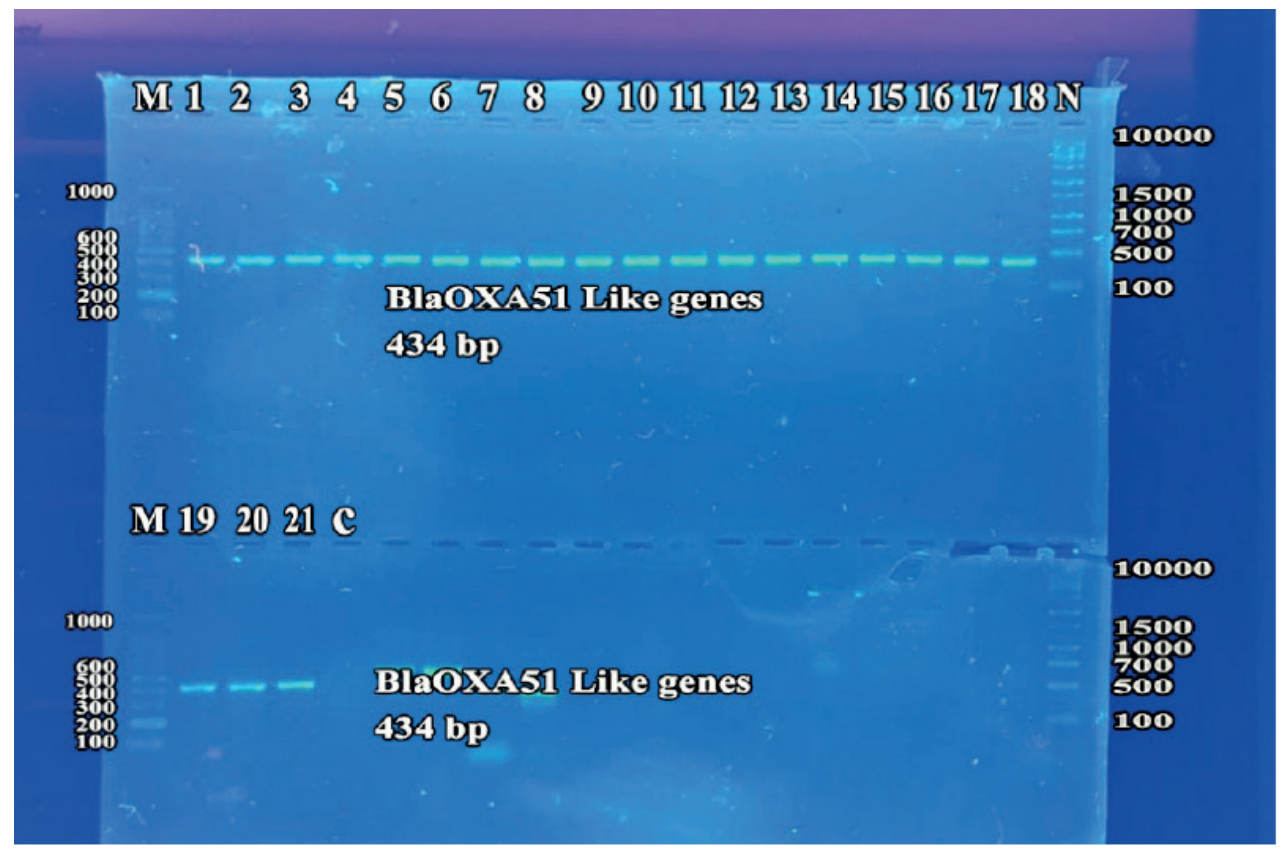

Figure 1. Detection of blaOXA51 like gene by monoplex PCR for A.baumannii isolates. lanes 1-21, XDR A.baumannii; Lane C, Negative control. Lane M, 100 bp DNA marker. Lane N, 1000 bp plus DNA marker. Detection was done on agarose gel (1.5\%) at 5 Volt/cm for 1.5 hours, stained by Red Safe dye, and imagined on a UV transilluminator documentation system.

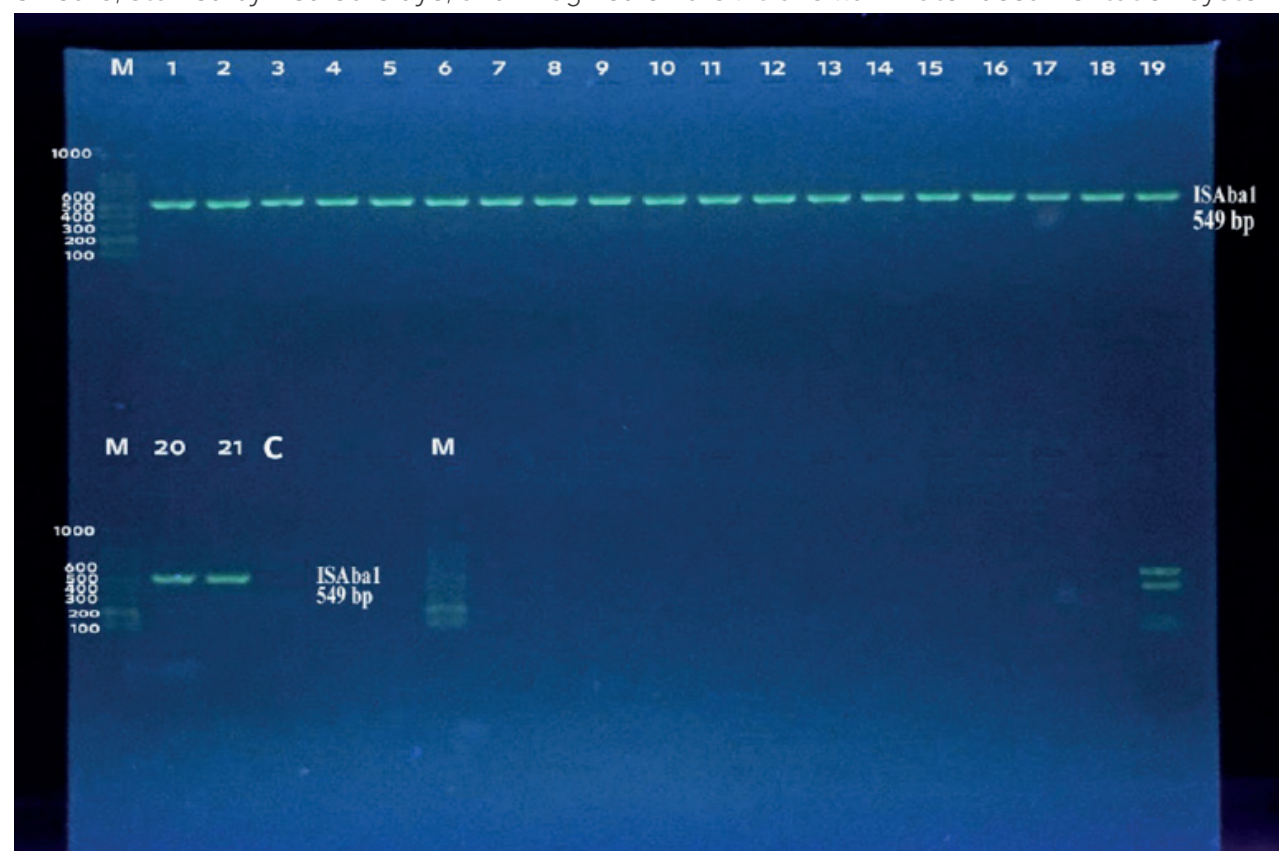

Figure 2. Detection of ISAbal gene by monoplex PCR of isolates. Lanes 1-21: XDR A.baumannii isolates. Lane C: Negative control. Lane M: 100 bp DNA marker. Detection was done on agarose gel (1.5\%) at 5 Volt/cm for 1.5 hours, stained by Red Safe dye, and imagined on a UV transilluminator documentation system.

Furthermore, because this gene was controlled by insertion sequences such as ISAbal, the presence of intrinsic chromosomally placed genes of the bla OXA-51-like gene did not correlate with the amount of carbapenem resistance of A.baumannii isolates ${ }^{31}$.

Additionally, all isolates of A.baumannii carried the Bla OXA-51-like gene and attributed the imipenem resistance state to the presence of ISAbal upstream of the blaoxa-51-like gene serves as a promoter for gene expression as one of these isolates' resistance methods ${ }^{32,33}$.

From 21 XDR A. baumannii isolates all have blaoxa-51 like genes. This corroborated those of previous local investigations ${ }^{26,34,35}$.
A study in Egypt revealed that genes encoding blaoxa-51 (belonging to class D carbapenemases) were found in $100 \%$ of the studied isolates ${ }^{36}$. According to research by Bahador et al., all 62 CRAB isolates tested positive for blaoxa-51-like genes ${ }^{37}$.

The present data could affirm that all A.baumannii isolates were positive for the ISAbal gene. It was found that the prevalence of ISAbal was $100 \%{ }^{27,36}$. ISAbal was the most common insertion element $(90.6 \%)^{38}$. The prevalence of ISAbal is equal to that seen in 59 Spanish isolates $(93.2 \%)^{39}$. While Taiwan $(36 \%)^{40}$ and India $(33 \%)^{41}$ have lower prevalence rates than the rest of the world. The presence of various insertion sequences in A. baumannii makes it resistant to carbapenems ${ }^{42}$.

These insertion sequences are found near genes that code 


\begin{tabular}{|c|c|c|c|c|c|c|}
\hline \multicolumn{7}{|c|}{ Gene: ISAba1(Forward) from A.baumannii( X9 isolate) } \\
\hline No. & $\begin{array}{c}\text { Type of } \\
\text { Substitution }\end{array}$ & Location & Nucleotide & $\begin{array}{c}\text { Sequence ID with } \\
\text { compare }\end{array}$ & Source & Identities \\
\hline 1 & Deletion & 52 & $-/ A$ & CP053098.1 & $\begin{array}{c}\text { Acinetobacter } \\
\text { baumannii }\end{array}$ & $99 \%$ \\
\hline
\end{tabular}

Table 3. Nucleotide changes of ISAbal(Forward) from Acinetobacter baumannii (X9 isolate) with Acinetobacter baumannii ATCC 17978 chromosome from the USA: San Diego.

\begin{tabular}{|l|l|l|}
\hline Feature & Studied isolate & Reference isolate \\
\hline Molecule Type & Genomic DNA & Genomic DNA \\
\hline Isolation Source & Swab & Fatal meningitis \\
\hline Host & Homo Sapiens & Homo Sapiens \\
\hline Country & Iraq, Baghdad & USA: San Diego \\
\hline
\end{tabular}

Table 4. ISAbal(Forward) features from Acinetobacter baumannii (X9 isolate) with Acinetobacter baumannii ATCC 17978 chromosome from the USA: San Diego.

Gene: ISAba1(Forward) from A.baumannii( X10 isolate)

\begin{tabular}{|c|l|c|c|c|c|l|}
\hline No. & \multicolumn{1}{|c|}{$\begin{array}{c}\text { Type of } \\
\text { substitution }\end{array}$} & Location & Nucleotide & $\begin{array}{c}\text { Sequence ID with } \\
\text { compare }\end{array}$ & Source & Identities \\
\cline { 1 - 4 } 1 & Deletion & 83 & $-/ \mathbf{A}$ & CP050388.1 & $\begin{array}{l}\text { Acinetobacter } \\
\text { baumannii }\end{array}$ & $\mathbf{9 9 \%}$ \\
\hline & Deletion & 85 & $-/ \mathbf{A}$ & & \\
\hline
\end{tabular}

Table 5. Nucleotide changes of ISAbal(Forward) from Acinetobacter baumannii (X10 isolate) with Acinetobacter baumannii strain VB473 chromosome from India.

\begin{tabular}{|l|l|l|}
\hline Feature & Studied Isolate & Reference Isolate \\
\hline Molecule Type & Genomic DNA & Genomic DNA \\
\hline Isolation Source & Swab & Sputum \\
\hline Host & Homo Sapiens & Homo Sapiens \\
\hline Country & Iraq, Baghdad & India \\
\hline
\end{tabular}

Table 6. Features of ISAbal(Forward) from Acinetobacter baumannii (X10 isolate) with Acinetobacter baumannii strain VB473 chromosome from India.

for several OXA-type carbapenemases and are implicated in their overexpression ${ }^{13}$.

\section{Conclusions}

In conclusion, $A$. baumannii is a significant pathogen in several nations. According to the findings of this study, it has a high resistance rate against most antibiotics, threatening in patients as a red alarm bacterium in hospitals, producing a high rate of death and morbidity due to its numerous mechanisms of resistance and the fact that it is not or only rarely treated with conventional antibiotics.

This bacterium can cause dangerous and long-term infections, especially in youngsters and people with immunological deficiencies. Our research focused on specific mobile components transported between species to change the antimicrobial pattern and enhance antimicrobial resistance. ISAbal has a high prevalence among extreme drug-resistant A. baumannii isolated from several Baghdad hospitals. Identifying these parameters can aid in controlling infection and reducing the microorganism's prevalence rate.

\section{Bibliographic references}

1. Montefour K, Frieden J, Hurst S, Helmich C, Headley D, Martin M, et al. Acinetobacter baumannii: an emerging multidrug-resistant pathogen in critical care. Crit Care Nurse. 2008;28(1):15-25.

2. Turton JF, Woodford N, Glover J, Yarde S, Kaufmann ME, Pitt TL. Identification of Acinetobacter baumannii by detection of the bla OXA-51-like carbapenemase gene intrinsic to this species. J Clin Microbiol. 2006;44(8):2974-6.

3. Cerqueira GM, Peleg AY. Insights into Acinetobacter baumannii pathogenicity. IUBMB Life. 2011;63:1055-60. doi: 10.1002/iub.533.

4. Peleg AY, Seifert H ,Paterson DL. Acinetobacter baumannii: emergence of a successful pathogen. Clin. Microbiol. 2008; 21(3): 538-582.

5. Bassetti M, Ginocchio F, Mikulska M. New treatment options against gram-negative organisms. Annu Updat Intensive Care Emerg Med 2011. 2011;501-15.

6. Rice LB: Federal funding for the study of antimicrobial resistance in nosocomial pathogens: No ESKAPE. J Infect Dis 2008, 197: 1079-1081.

7. Vrancianu CO, Gheorghe I, Czobor IB, Chifiriuc MC. Antibiotic Resistance Profiles, Molecular Mechanisms and Innovative Treatment Strategies of Acinetobacter baumannii. Microorganisms. 2020;8(6):935. Published 202021 June. doi:10.3390/microorganisms 8060935 
Acinetobacter baumannii ATCC 17978 chromosome, complete genome Sequence ID: CP053098.1Length: 4005343Number of Matches: 1

Range 1: 3737775 to 3738256

\begin{tabular}{|l|l|l|l|l|}
\hline Score & Expect & Identities & Gaps & Strand \\
\hline 883 bits(478) & 0.0 & $\mathbf{4 8 1 / 4 8 2 ( 9 9 \% )}$ & $\mathbf{1 / 4 8 2 ( 0 \% )}$ & Plus/Minus \\
\hline
\end{tabular}

\begin{tabular}{|c|c|c|}
\hline Query & 2 & 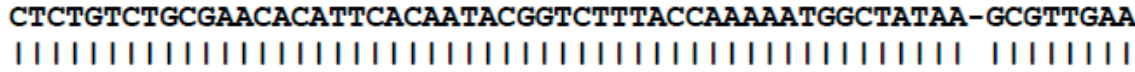 \\
\hline Sbjet & 3738256 & СTCTGTCTGCGAACACATTCACAATACGGTCTTTACCAAAAATGGCTATAAAGCGTTGAA \\
\hline Query & 61 & $\begin{array}{l}\text { TCAAAGCAATACGCTCTTTCGTATCTGAATTTCCACGTTTATTAAGCAATGTCCAAAGGA } \\
1111111111111111111111111111111111111111111111111111111111\end{array}$ \\
\hline Sbjet & 3738196 & TCAAAGCAATACGCTCTTTCGTATCTGAATTTCCACGTTTATTAAGCAATGTCCAAAGGA \\
\hline Query & 121 & TAGGTATCGCTATTCCACGATAAACGATTGCGAGCATCAGGATATTAATATTTCGTTTTC \\
\hline Sbjet & 3738136 & 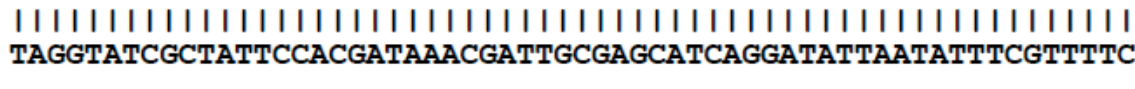 \\
\hline Query & 181 & $\begin{array}{l}\text { CCCATTTCCAATTGGTTCTATCTAAAGTCAGTTGCACTTGGTCGAATGAAAACATATTGA } \\
1111111111111111111111111111111111111111111111111111\end{array}$ \\
\hline Sbjet & 3738076 & CCCATTTCCAATTGGTTCTATCTAAAGTCAGTTGCACTTGGTCGAATGAAAACATATTGA \\
\hline Query & 241 & $\begin{array}{l}\text { AAATCAACTGAGAAATTGACGATAATCAAAATACTGACCTGCAAAGAAGCGCTGCATAC } \\
1111111111111111111111111111111111111111111111111111\end{array}$ \\
\hline Sbjet & 3738016 & AAATCAACTGAGAAATTTGACGATAATCAAAATACTGACCTGCAAAGAAGCGCTGCATAC \\
\hline Query & 301 & 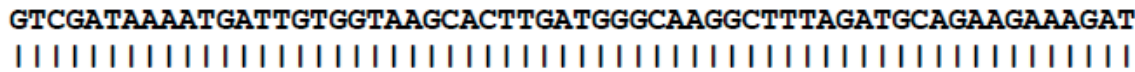 \\
\hline Sbjet & 3737956 & GTCGATAAAATGATTGTGGTAAGCACTTGATGGGCAAGGCTTTAGATGCAGAAGAAAGAT \\
\hline Query & 361 & 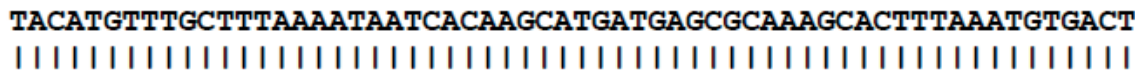 \\
\hline Sbjet & 3737896 & TACATGTTTGCTTTAAAATAATCACAAGCATGATGAGCGCAAAGCACTTTAAATGTGACT \\
\hline Query & 421 & $\begin{array}{l}\text { TGTCCATTTAAGATATTGTTAAAGATAAGATATAACTCATTGAGATGTGTCATAGTAT } \\
\text { IIIIIIIIIIIIIIIIIIIIIIIIIIIIIIIIIIIIIIIIIIIIIIIIII }\end{array}$ \\
\hline Sbjet & 3737836 & TGTTCCATTTTAGATATTTGTTTAAGATAAGATATAACTCATTGAGATGTGTCATAGTAT \\
\hline Query & 481 & $\begin{array}{l}\text { TC } \\
11\end{array}$ \\
\hline
\end{tabular}

60

3738197

120

3738137

180

3738077

240

3738017

300

3737957

360

3737897

420

3737837

480

3737777

Figure 3. Sequence alignment of ISAbal(Forward) of A.baumannii( X9 isolate) with Acinetobacter baumannii ATCC 17978 chromosome from USA: San Diego.

8. Siguier P, Filée J, Chandler M. Insertion sequences in prokaryotic genomes. Curr Opin Microbiol. 2006;9(5):526-31.

9. Siguier P, Gourbeyre E, Chandler M. Bacterial insertion sequences: their genomic impact and diversity. FEMS Microbiol Rev. 2014;38(5):865-91.

10. Montaña S, Almuzara M, Pennini M, et al. IS CR2 and IS 26: two insertion sequences highly dispersed among Acinetobacter spp. clinical strains. J Bacteriol Mycol Open Access. 2017;4(1):33-36.

11. Campbell N A, and J B. Reece. Biology (6th ed.) Benjamin Cummings, San Francisco. 2002; pp. 345-346

12. Naas T, Namdari F, Réglier-Poupet H, Poyart C, Nordmann P. Panresistant extended-spectrum 囚-lactamase SHV-5-producing Acinetobacter baumannii from New York City. J Antimicrob Chemother. 2007;60(5):1174-6.

13. Corvec S, Caroff N, Espaze E, Giraudeau C, Drugeon H, Reynaud A. AmpC cephalosporinase hyperproduction in Acinetobacter baumannii clinical strains. J Antimicrob Chemother .2003; 52:629-635

14. Héritier C, L. Poirel, P. Nordmann. Cephalosporinase over-expresssion resulting from insertion of ISAbal in Acinetobacter baumannii. Clin. Microbiol. Infect. 2006;12123-130.
15. Corvec S, Poirel L, Naas T, Drugeon H, Nordmann P. Genetics and expression of the carbapenem-hydrolyzing oxacillinase gene bla OXA-23 in Acinetobacter baumannii . Antimicrob Agents Chemother. 2007;51(4):1530-3.

16. Turton J F, Woodford N, Glover J, Yarde S, Kaufmann M E ,Pitt $T L$. Identification of Acinetobacter baumannii by detection of the blaOXA 51-like carbapenemase gene intrinsic to this species. J. Clin. Microbiol. 2006a; 44(8): 2974-2976.

17. Bogaerts P, G. Cuzon, T. Naas, C. Bauraing, A. Deplano, B. Lissoir, P. Nordmann, and Y. Glupczynski. Carbapenem-resistant Acinetobacter baumannii isolates expressing the blaOXA-23 gene associated with ISAba4 in Belgium. Antimicrob Agents Chemother. 2008; 52: 4205-4206.

18. Poirel L, Nordmann P. Genetic structures at the origin of acquisition and expression of the carbapenem-hydrolyzing oxacillinase gene bla OXA-58 in Acinetobacter baumannii. Antimicrob Agents Chemother. 2006;50(4):1442-8

19. Forbes BA, Sahm DF, Weissfeld AS. Diagnostic microbiology. Mosby St Louis; 2007. 
Acinetobacter baumannii strain VB473 chromosome, complete genome Sequence ID: CP050388.1Length: 3948250Number of Matches: 27

Range 1: 164726 to 165214

\begin{tabular}{lllll}
\hline Score & Expect & Identities & Gaps & Strand \\
\hline 891 bits(482) & 0.0 & $487 / 489(99 \%)$ & $2 / 489(0 \%)$ & Plus/Plus
\end{tabular}

\begin{tabular}{|c|c|c|c|}
\hline Query & 2 & GATAAACTCTCTGTCTGCGAACACATTCACAATACGGTCTTTACCAAAAATGGCTATAAA & 61 \\
\hline Sbjct & 164726 & GATAAACTCTCTGTCTGCGAACACATTCACAATACGGTCTTTACCAAAAATGGCTATAAA & 164785 \\
\hline Query & 62 & 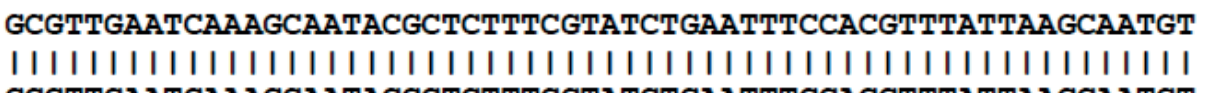 & 121 \\
\hline Sbjet & 164786 & GCGTTGAATCAAAGCAATACGCTCTTTCGTATCTGAATTTCCACGTTTATTAAGCAATGT & 164845 \\
\hline Query & 122 & 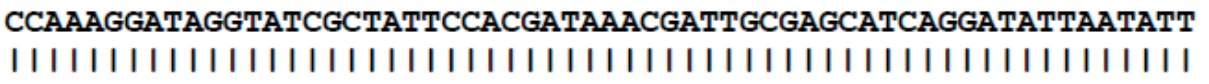 & 181 \\
\hline Sbjet & 164846 & CCAAAGGATAGGTATCGCTATTCCACGATAAACGATTGCGAGCATCAGGATATTAATATT & 164905 \\
\hline Query & 182 & \multirow{2}{*}{$\begin{array}{l}\text { TCGTTTCCCCATTTCCAATGGTTCTATCTAAAGTCAGTTGCACTTGGTCGAATGAAAA } \\
111111111111111111111111111111111111111111111111\end{array}$} & 241 \\
\hline Sbjet & 164906 & & 164965 \\
\hline Query & 242 & \multirow{2}{*}{ 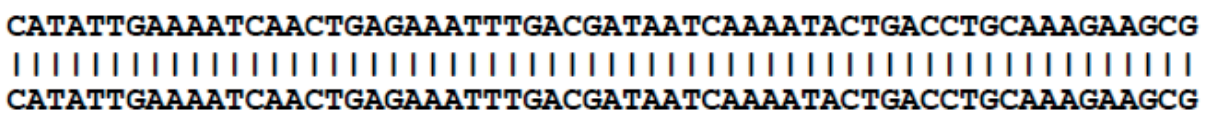 } & 301 \\
\hline Sbjet & 164966 & & 165025 \\
\hline Query & 302 & СTGCATACGTCGATAAAATGATTGTGGTAAGCACTTGATGGGCAAGGCTTTAGATGCAGA & 361 \\
\hline Sbjet & 165026 & 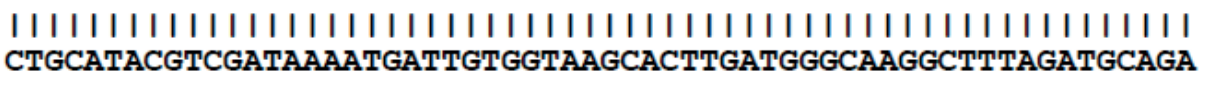 & 165085 \\
\hline Query & 362 & 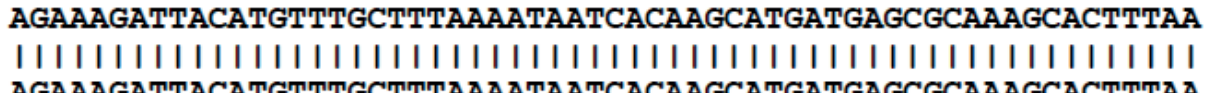 & 421 \\
\hline Sbjet & 165086 & AGAAAGATTACATGTTTGCTTTAAAATAATCACAAGCATGATGAGCGCAAAGCACTTTAA & 165145 \\
\hline Query & 422 & \multirow{2}{*}{ 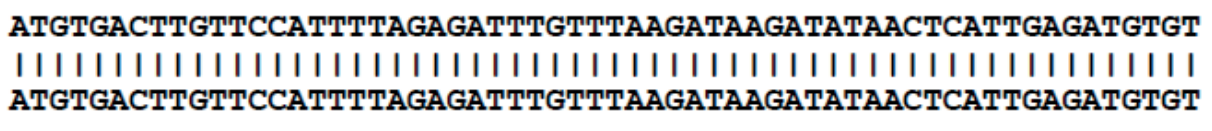 } & 481 \\
\hline Sbjet & 165146 & & 165205 \\
\hline Query & 482 & \multirow{2}{*}{$\begin{array}{l}\text { C-T-GTATT } \\
\text { I I IIIII } \\
\text { CATAGTATT }\end{array}$} & \\
\hline Sbjet & 165206 & & \\
\hline
\end{tabular}

Figure 4. Sequence alignment of ISAbal(Forward) of A.baumannii( X10 isolate) with Acinetobacter baumannii strain VB473 chromosome, from India.

20.Brooks G F, Carroll KC, Butel JS, Morse S A, Mietzner,T.A. Medical Microbiology. Jawetz, Melnick and adelberg's. McGraw-Hill Companies, Inc. USA 2013; 26th ed.

21. Ling T K, Liu Z K, Cheng A F. Evaluation of the vitek 2 system for rapid direct identification and susceptibility testing of gram-negative bacilli from positive blood cultures. Journal of clinical microbiology.2003; 41(10): 4705-4707. .

22. CLSI. Performance Standards for Antimicrobial Susceptibility Testing. 30th ed. CLSI supplement M100.Wayne, PA: Clinical and Laboratory Standards Institute; 2020.

23. Asif M, Alvi IA, Rehman SU. Insight into Acinetobacter baumannii : pathogenesis, global resistance, mechanisms of resistance, treatment options, and alternative modalities. Infect Drug Resist. 2018;11:1249-1260
24. Kempf M, Rolain JM .Emergence of resistance to carbapenems in Acinetobacter baumannii in Europe: clinical impact and therapeutic options. Int J Antimicrob Agents .2012; 39: 105-114. pmid:22113193].

25. Higgins PG, Dammhayn C, Hackel M, Seifert H. Global spread of carbapenem-resistant Acinetobacter baumannii . J Antimicrob Chemother. 2010;65(2):233-8.

26. Fatima S. Assessment correlation between biofilm formation and type II toxin-antitoxin system in imipenem-resistant Acinetobacter baumannii. Submitted to the Council of College of Science / Mustansiriyah University In Partial Fulfillment of the Requirements for the Degree of Doctor of Philosophy (Ph.D.) in Biology/ Microbiology. 2018 
27. Owrang M, Fallah F, Irani S, Rahbar M, Eslami G. Identification and Isolation of Insertion Sequences, in Carbapenem Resistant Clinical Isolates of Acinetobacter baumannii from Tehran Hospitals, Jundishapur J Microbiol. 2018 ; 11(6):e58251. doi: 10.5812/ jjm.58251

28. McConnell MJ, Domínguez-Herrera J, Smani Y, López-Rojas R, Docobo-Pérez F, Pachón J. Vaccination with outer membrane complexes elicits rapid protective immunity to multidrug-resistant Acinetobacter baumannii . Infect Immun. 2011;79:518-26.

29.Turton JF, Ward ME, Woodford N, Kaufmann M E, Pike R, Livermore D M ,Pitt T L. The role of ISAbal in expression of OXA carbapen emase genes in Acinetobacter baumannii. FEMS Microbiol. Lett. 2006b; 258(1):72-77.

30.Evans B A, Hamouda A, Towner K J ,Amyes S G. OXA-51-like beta-lactamases and their association with particular epidemic lineages of Acinetobacter baumannii. Clin. Microbiol. Infect. 2008;14(3): 268-275

31. Woodford N, Ellington MJ, Coelho JM, Turton JF, Ward ME, Brown S, et al. Multiplex PCR for genes encoding prevalent OXA carbapenemases in Acinetobacter spp. Int J Antimicrob Agents. 2006;27(4):351-3.

32. Alexandre P Zavascki, Cecília G Carvalhaes, Renata C Picão \& Ana C Gales. Multidrug-resistant Pseudomonas aeruginosa and Acinetobacter baumannii: resistance mechanisms and implications for therapy, Expert Review of Anti-infective Therapy.2010; 8:1, 71-93.

33. Sohrabi B, Vanani IR, Tahmasebipur K, Fazli S. An exploratory analysis of hotel selection factors: A comprehensive survey of Tehran hotels. Int J Hosp Manag. 2012;31(1):96-106.

34. Ghaima K K, Saadedin S M K, Jassim K A. Isolation, molecular identification and antimicrobial susceptibility ofAcinetobacter baumannii isolated from Baghdad. Int. J. Sci. Res. Publ. 2016; 6(5): 351-356

35. Hussein N H, Al-Mathkhury H J F, Sabbah M A. Imipenem-Resist ant Acinetobacter baumannii isolated from patients and hospitals environment in Baghdad. Iraqi J. Sci. 2013; 54(4): 803-812
36. Abouelfetouh A, Torky AS, Aboulmagd E. Phenotypic and genotypic characterization of carbapenem-resistant Acinetobacter baumannii isolates from Egypt. Antimicrob Resist Infect Control. 2019;8(1):1-9

37. Bahador A, Raoo An, R Farshadzadeh Z, Beitollahi L, Khaledi A Rahimi S, Mokhtaran M, Mehrabi Tavana A, Esmaeili D. The Prevalence of IS Aba 1 and IS Aba 4 in Acinetobacter baumannii Species of Different International Clone Lineages Among Patients With Burning in Tehran, Iran. Jundishapur journal of microbiology.2015; 8(7), e17167.

38. Alsultan AA, Aboulmagd E, Evans BA, Amyes SG. Clonal diversity of Acinetobacter baumannii from diabetic patients in Saudi Arabian hospitals. J Med Microbiol. 2014;63(11):1460-6.

39. Villalón P., Valdezate S., Medina-Pascual M.J., Carrasco G., Vindel A., Saez-Nieto J. A. 2013; Epidemiology of the Acinetobacter-derived cephalosporinase, carbapenem-hydrolysing oxacillinase and metallo- $囚$-lactamase genes, and of common insertion sequences, in epidemic clones of Acinetobacter baumannii from Spain. J Antimicrob Chemother 68:550-553

40.Lu P L, Doumith M, Livermore D M, Chen T P, Woodford N.Diversity of carbapenem resistance mechanisms in Acinetobacter baumannii from a Taiwan hospital: spread of plasmid-borne OXA72 carbapenemase. J Antimicrob Chemother .2009; 63:641-647

41. Karunasagar A, Maiti B, Shekar M, Shenoy M S, Karunasagar I. Prevalence of OXA囚type carbapenemase genes and genetic heterogeneity in clinical isolates of Acinetobacter spp. from Mangalore, India. Microbiol Immunol. 2011;55(4):239-46.

42.Lee K, Yong D, Jeong SH, Chong Y. Multidrug-resistant Acinetobacter spp.: increasingly problematic nosocomial pathogens. Yonsei Med J. 2011;52(6):879-91.

Received: 7 August 2021

Accepted: 21 September 202 